\title{
Setor Madeireiro: uma análise de sua contribuição à balança comercial e à economia de Roraima
}

Desde o período colonial os produtos florestais fazem parte do comércio exterior de vários estados que compõem a Amazônia legal. Este fator contribui com a economia de vários municípios, gerando empregos e renda. Inserido nesse contexto, todos os municípios do estado de Roraima estão envolvidos com a atividade madeireira e apresentam dados relevantes na produção destinada tanto ao mercado interno quanto ao externo, gerando efeitos multiplicadores na economia. Assim, o objetivo desse trabalho é analisar a contribuição do setor madeireiro na balança comercial do estado de Roraima no período de 1989 a 2018 , apresentando a importância do setor para a geração de emprego e renda na economia. Para alcançar esse fim, utilizou-se a pesquisa descritiva combinada com a pesquisa bibliográfica, que permitiu analisar os dados referentes ao comércio exterior, Produto Interno Bruto e Renda, com o subsídio das literaturas que tratam do tema. Os resultados apontaram que a contribuição do setor madeireiro no comércio exterior deve-se às vantagens absolutas e relativas, à abundância de fatores de produção (recursos florestais) e à capacidade de influenciar o crescimento de outras atividades ao proporcionar impactos nos níveis de produto, emprego e renda. Os dados demonstram a influência do setor madeireiro no comércio exterior com efeitos encadeantes para o mercado interno.

Palavras-chave: Setor Madeireiro; Comércio Exterior; Produto; Emprego; Renda.

\section{Wood Industry: An Analysis of Its Contribution to Roraima's Trade Balance and Economy}

Since the colonial period, forest products are part of the foreign trade of the several states that make up the legal Amazon. This factor contributes to the econom of several municipalities, generating jobs and income. In this context, all municipalities of the state of Roraima are involved in logging and they make up for a relevant part of the production, for both domestic and foreign markets, which generates a multiplier effect on their economy. Thus, the objective of this paper is to analyze the contribution of the timber sector to Roraima's trade balance from 1989 to 2018, showing the sector's importance in the economy, generating jobs and income. To achieve this end, we used both descriptive and bibliographic research, which allowed us to analyze data related to foreign trade, Gross Domestic Product and Income, with the support of the literature on the subject. The results show that the contribution of the timber sector in foreign trade is due to the absolute and relative advantages, the abundance of production factors (forest resources) and the ability to influence the growth of other activities by providing impacts on output levels, employment and income. The data demonstrates the influence of the timber sector on foreign trade with dazzling effects for the domestic market.

Keywords: Timber Sector; Foreign Trade; Product; Job; Income.

Topic: Ciências Florestais

Reviewed anonymously in the process of blind peer.
Received: $12 / 08 / 2019$

Approved: 27/09/2019
Michelle de Oliveira Barbosa Veras (iD) Instituto Federal de Roraima, Brasil http://lattes.cnpq.br/8072307086539428 http://orcid.org/0000-0002-9985-0560

michelleswm@yahoo.com.br

Sandra Maria Franco Buenafuente (iD) Universidade Federal de Roraima, Brasil http://lattes.cnpq.br/7018219463846256 http://orcid.org/0000-0003-2549-3596 sanma239@hotmail.com

\section{Referencing this:}

VERAS, M. O. B.; BUENAFRUENTE, S. M. F.. Setor Madeireiro: uma análise de sua contribuição à balança comercial e à economia de Roraima. Revista Ibero Americana de Ciências Ambientais, v.10, n.5, p.22-35, 2019. DOI: http://doi.org/10.6008/CBPC21796858.2019 .005 .0003 


\section{INTRODUÇÃO}

Com a globalização da economia, a partir da abertura econômica no contexto internacional nos anos de 1990, se evidenciaram importantes transformações no cenário das economias em desenvolvimento. Nas transações comerciais de recursos naturais, a exportação de madeira cumpre um papel importante nestas transações. A Amazônia com uma extensa cobertura florestal oferece potencial favorável para a exploração desse recurso, embora este processo seja responsável pela alteração parcial da floresta, também contribui para a geração de emprego e renda, nos estados da região.

O estado de Roraima possui grande potencialidade para o setor madeireiro, imensa riqueza de recursos minerais e vocação agropecuária, face à extensão florestal e campos naturais/savanas. A cobertura vegetal do estado é composta principalmente por florestas, com números crescentes na produção de madeira para o mercado interno e externo. Historicamente, os recursos naturais foram subutilizados e explorados de forma indevida, mas atualmente buscam-se mecanismos de sustentação do sistema de exploração para a conquista de mercados, tendo em vista a potencialidade do setor para geração de recursos para o desenvolvimento regional (BENCHIMOL, 1997; AGNELO, 1998).

Atualmente, o setor madeireiro tem relevância na geração de empregos e, sobretudo, tem peso no Produto Interno Bruto da região Amazônica e contribui de forma significativa com o comércio exterior de todos os estados que compõe a Amazônia legal. Nesse sentido, o objetivo desse trabalho é analisar a contribuição do setor madeireiro na balança comercial do estado de Roraima no período de 1989 a 2018, bem como sua importância na economia do Estado, através do estudo dos efeitos do setor na geração de produto, empregos e renda na economia.

Para subsidiar a pesquisa, foram utilizadas bibliografias que tratam do tema a fim de dar sustentação à descrição de dados coletados principalmente no Ministério do Desenvolvimento, Indústria e Comércio exterior (MDIC), através do sistema Aliceweb e Comex Stat, com o apoio das principais teorias do comércio internacional e dos dados coletados principalmente do Instituto Brasileiro de Geografia e Estatística (IBGE). O desenvolvimento do artigo conta com quatro tópicos. O primeiro contextualiza as principais teorias do comércio internacional; o segundo busca caracterizar a Amazônia, Estado de Roraima e o setor madeireiro, considerando aspectos do PIB de Roraima e geração de emprego e renda; o terceiro discorre sobre os aspectos históricos e econômicos da atividade madeireira em Roraima; e por fim, o quarto evidencia a análise da contribuição do setor madeireiro à balança comercial do Estado.

\section{REVISÃO TEÓRICA}

\section{Contextualização Teórica do Comércio Internacional}

Na Antiguidade, o homem produzia todos os bens necessários a sua sobrevivência, com o tempo percebeu que seu semelhante poderia necessitar de um bem que produzia em excedente, surgindo a necessidade de comércio. A primeira corrente de pensamento orientada para a regulação das relações comerciais foi o mercantilismo (1500 a 1800), que defendia o acúmulo de metais preciosos através de 
estimulo às exportações e restrição às importações para garantir uma balança comercial favorável. Essa doutrina defendia que a regulamentação do comércio iria promover a riqueza da nação a curto e longo prazos (MEIRELHES, 1982; CARBAUGH, 2004).

De acordo com Carbaugh (2004), o maior crítico dessa corrente foi Adam Smith, economista clássico que defendeu que o comércio deveria ser livre, pois a 'mão invisível' da economia faria com que a concorrência beneficiasse toda a sociedade, promovendo especialização internacional. Smith apresentou a primeira justificação teórica para o comércio entre as nações com a teoria das vantagens absolutas, que defende o livre comércio para as nações se especializarem em produtos que produzem de maneira mais barata, de modo que haveria uma divisão internacional do trabalho e todos ganhariam com as trocas.

Como um aperfeiçoamento desse princípio, foi defendida a teoria das vantagens comparativas, onde demonstrou que não seria necessária a vantagem absoluta para que o comércio fosse vantajoso. Mesmo que determinado país apresente vantagem absoluta em todos os bens, o comércio ainda será vantajoso, se o país em desvantagem se especializasse no bem que possuísse vantagem comparativa. "Um país possui uma vantagem comparativa na produção de um bem se o custo de oportunidade da produção desse bem em relação aos demais é mais baixo nesse país do que em outros" (SILVA, 1987; KRUGMAN et al., 2005).

O custo de oportunidade leva em conta os fatores de produção na produção de bens, e a escolha de cada bem dependerá do custo para sacrificar a produção de outros, dado o limite dos fatores disponíveis (KRUGMAN et al., 2005). Por exemplo, se o custo de oportunidade de produzir madeira for menor no Brasil do que na Venezuela, o Brasil exportaria madeira para Venezuela e importaria um bem cujo custo de oportunidade fosse mais alto no Brasil, de modo que o comércio seria vantajoso mesmo que a Venezuela possuísse vantagem absoluta em todos os bens. O Brasil ganharia exportando madeira, e também a Venezuela, visto que deixaria de sacrificar a produção de outros bens para produzir madeira.

Com o fim de explicar os efeitos do comércio sobre a distribuição de renda, a teoria neoclássica desenvolveu o modelo Hecsher-ohlin. Esse modelo considera a influência dos fatores de produção na determinação do comércio, de modo que os países se especializam na produção de bens que utilizam fatores de produção que são abundantes, em troca de bens cujos fatores são escassos. Assim, os países estariam indiretamente comercializando fatores de produção, de modo que a demanda pelo fator escasso cai (o preço do bem diminui) e aumenta a demanda pelo fator abundante (o preço do bem aumenta), com o efeito inverso no outro país, levando à equalização dos fatores e preços relativos, mas com uma distribuição de renda desigual (KRUGMAN et al., 2005).

No começo da década de 1980, surge uma explicação endógena sobre os sistemas de especialização regional baseados na existência de rendimentos crescentes de escala. Este pressuposto teórico se transforma na base da nova teoria do comercio internacional. O surgimento da nova teoria, que enfatizava o crescimento endógeno, se diferenciava da teoria neoclássica do comercio internacional, por ter como referência a presença de rendimentos crescentes a escala e de economias externas. Estes fatores eram elementos chave 
para explicar o crescimento sustentável (KRUGMAN et al., 1985; KRUGMAN et al., 1990)ํ․

Outra contribuição para explicar os efeitos do comércio exterior sobre a economia dos países é a teoria da base exportadora, elaborada inicialmente por North. Este explica que a medida que as regiões crescem em torno de uma base de exportação ocorre uma melhora do custo competitivo dos produtos exportados. "Os produtos primários de exportação desempenham papel igualmente vital na sensibilidade cíclica da região; através deles as mudanças do nível de renda de outras regiões se fazem sentir na economiaobjeto" (NORTH, 1955).

De acordo com a teoria da base de exportação, esta desempenha um papel vital na determinação do nível de renda absoluta e 'per capita' de uma região. E com o crescimento da renda e da população, o capital investido fluem para as indústrias de exportação até determinado ponto, e a partir deste, fluem para outras atividades. North (1955) explica que o declínio de um produto de exportação deve ser acompanhado pelo crescimento de outros, e as entre as principais razões o autor cita "as mudanças na demanda exterior à região, a exaustão de um recurso natural, os custos crescentes de terra ou trabalho, em relação aos de uma região competidora, e as mudanças tecnológicas". Outra razão apontada é o desenvolvimento dos transportes. Acerca da influência no nível de renda, o autor argumenta:

A importância da base de exportação é o resultado de seu papel básico na determinação do nível de renda absoluta e per capita de uma região, e consequentemente, na determinação da quantidade de atividades locais, secundárias e terciárias, que se desenvolverão. A base da exportação também influenciou significativamente o tipo de indústria subsidiária, a distribuição da população e o padrão de urbanização, o tipo de força de trabalho, as atitudes sociais e políticas da região e sua sensibilidade a flutuações da renda e do emprego. (NORTH 1955)

Observa-se, dessa forma, a contribuição das teorias do comércio internacional para explicar os efeitos do comércio no nível de crescimento, emprego e renda locais.

\section{Amazônia e o Setor Madeireiro}

A Amazônia brasileira é uma das principais produtoras de madeira tropical do mundo. A atividade madeireira movimenta a economia de vários municípios, juntamente com o setor de mineração e agropecuária. A partir de 1970, três fatores contribuíram para o crescimento do setor: a abertura de estradas, possibilitando o acesso; custo de aquisição baixo; e o esgotamento dos estoques madeireiros do sul do país. Essas condições impulsionaram o setor tornando a atividade madeireira de grande importância na região (HUMMEL et al., 2010).

Essa importância pode ser constatada considerando que os recursos florestais madeireiros têm um peso significativo no PIB da região Amazônica, provocando uma inversão do quadro exploração desenfreada estabelecida nas décadas de 60 e 70, quando a floresta era desmatada dando lugar a pecuária e agricultura, enquanto os recursos madeireiros eram subutilizados. Atualmente, o setor madeireiro tem oferecido parte dos recursos para subsidiar o desenvolvimento regional, conforme Agnelo (1998):

12 O conjunto de ideias definidas da nova Teoria do Comércio Internacional foram originalmente mencionados por Dixit et al. (1989), Krugman (1979, 1980 e 1981) e Helpman (1984). 
Atualmente, os recursos naturais estão fornecendo parte do capital para o desenvolvimento regional. Observa-se claramente que o modelo de desenvolvimento da Amazônia está se transformando de um modelo subsidiado pelo governo em outro, com base na exploração da riqueza dos recursos locais. De certa forma, do ponto de vista florestal, isso é desejável, pois os recursos que antes eram queimados agora estão sendo aproveitados.

Nos estados da Amazônia Ocidental (Amazonas, Acre, Roraima e Rondônia) a forma de exploração adotada é a seletiva, normalmente realizada em floresta nativa sem adequado manejo, possuindo baixa produtividade e pouca reposição dos recursos florestais. O desmatamento ilegal reponde por cerca de $80 \%$ da extração madeireira, tornando-se um dado preocupante tendo em vista a crescente demanda do setor (PARENTE et al., 2003).

Em relação às formas de exploração, a floresta Amazônica se divide em dois tipos principais, a floresta de várzea, com uma superfície de 18 a 20 milhões de hectares, situada em terrenos baixos com alagamentos periódicos; e floresta de terra-firme, com uma superfície de 253 milhões de hectares, situada em terras altas que não sofrem efeito de enchentes. Quanto à potencialidade de exploração, Agnelo (1998) afirma que cerca de 15 bilhões de metros cúbicos estão em condições de exploração.

De acordo com Pereira et al. (2010), na Amazônia existem 71 polos madeireiros ${ }^{2}$ distribuídos pelos estados, 2.227 empresas atuando no setor, com um consumo em toras de $14.148 .000 \mathrm{~m}^{3}$, gerando uma receita bruta de 2,4 bilhões de dólares em 2009. O consumo em toras rendeu uma produção de 5.808 .000 $\mathrm{m}^{3}$ de madeira processada, sendo $72 \%$ madeira serrada, $15 \%$ beneficiada na forma de portas, janelas e etc. e $13 \%$ painéis laminados e compensados. O rendimento médio do processamento foi de apenas $41 \%$. De acordo com Parente et al. (2003), o setor de laminados e compensados e o de serrarias apresentam-se consolidados na Amazônia, enquanto a indústria de móveis ainda se apresenta incipiente. Em 2009, o setor madeireiro gerou 203.750 empregos na Amazônia legal, distribuídos entre empregos diretos na indústria madeireira (44.676) e áreas de extração (21.963) e empregos indiretos (137.066), com a participação de 2\% da população economicamente ocupada.

Em relação ao destino da madeira processada, Hummel et al. (2010) explica que, em 1998, 79\% da madeira processada na forma de produtos semi-industrializados e industrializados destinou-se ao mercado nacional, 7\% para os estados da Amazônia legal e 14\% para exportação. Em 2004, o mercado nacional teve sua participação reduzida para 53\%, Amazônia legal para 11\%, enquanto o setor externo ampliou sua participação para 36\%. Já em 2009, o mercado nacional participa com 62\%, a Amazônia legal com 17\% e o setor externo com $21 \%$. Quanto aos resíduos do processamento da madeira, 19\% foi o carvão, 18\% para olaria, $16 \%$ entulho, $14 \%$ energia, $9 \%$ queima e $24 \%$ outras destinações (PEREIRA et al., 2010).

\section{Aspectos Históricos e Econômicos da Atividade Madeireira em Roraima}

Integrante da Amazônia Legal, Roraima compreende uma área de 224.301,04 km², inserida no conceito de bioma Amazônico. Sua cobertura vegetal é composta principalmente por florestas, com 62,7\% da cobertura total ao sul, $34,7 \%$ áreas de savanas ou campos naturais localizadas na região centro/norte-

\footnotetext{
${ }^{2}$ De acordo com Hummel et al. (2010), uma localidade é considerada polo madeireiro quando o volume e sua extração e consumo anual de madeira em tora é igual ou superior a 100 mil metros cúbicos.
} 
nordeste, sendo 6,59\% de área desmatada até 2009, com a distribuição do desmatamento maior nos municípios de Mucajaí, Cantá e Rorainópolis, de acordo com o INPE (2018) (SILVA et al., 2008; PEREIRA et al., 2010).

O estado de Roraima, capital Boa Vista, possui a menor população do país, um total de quinze municípios, 450.479 habitantes, sendo que $76,55 \%$ residem em área urbana e $23,45 \%$ em área rural, com uma densidade demográfica de 2,01 hab/ $\mathrm{km}^{2}$. Segundo informações da pesquisa "Projeções da População do Brasil e Unidades da Federação 2010-2060" do IBGE, a população de Roraima em 2019 ultrapassará 600 mil habitantes. O estado faz fronteira ao norte com a Venezuela e a República Cooperativa da Guiana, ao sul com os Estados do Amazonas e Pará, a leste com República Cooperativa da Guiana e a oeste com o Estado do Amazonas e com a Venezuela (IBGE, 2010).

Em relação à paisagem física, Roraima possui três regiões, de acordo com Magalhães (2008): Baixo Rio Branco (floresta densa) - região sul; Alto Rio Branco (vegetação de campos) - região norte e central; e região montanhosa, composta por serras ao longo da fronteira com os países vizinhos. Historicamente, o setor madeireiro dependia quase que exclusivamente do mercado externo, sofrendo grande impacto entre 1979 e 1984, com a quase completa paralização das exportações para a Venezuela, que era o único país comprador. O motivo para a crise foi a política de arrocho cambial e fiscal adotada pelo governo venezuelano que impôs várias barreiras à importação de produtos madeireiros de alguns países que não faziam parte do "Pacto Andino" (BARBOSA, 1990).

De acordo com o autor, em 1981 o mercado externo demandou 74,7\% da produção de madeira local, tendo como único comprador a Venezuela, decrescendo em 1984 para 13,7\% até chegar a 0,14\% em 1988. A partir de 1987, observa-se um aumento dessa produção voltada ao mercado interno, com destaque para região sul do estado. A descoberta do ouro em áreas indígenas e a migração de pessoas para a região contribuição para a sustentação do mercado interno. Formaram-se dois grandes polos madeireiros no estado, um na região norte (Boa Vista, Bonfim, Alto Alegre e Mucajaí) e outro na região sul (Caracarí, São Luiz do Anauá e São João da Baliza). O mercado da região norte foi aquecido pela demanda da construção civil pelos imigrantes, que se instalaram principalmente na capital Boa Vista. A região sul tinha um mercado promissor que era o estado do Amazonas, que adquiriu 68,65\% da produção total de 1988.

Barbosa (1990) afirma que no início da década de 80 a maioria das empresas localizava-se em Boa Vista, por conta da facilidade de negócios e estrutura melhor em relação a outros municípios. A queda da participação deu-se por conta do surgimento de outras empresas nos outros municípios, principalmente no sul do estado, por apresentar os maiores potenciais madeireiros. Com o aumento da demanda local e a procura pelo estado do Amazonas, a região sul teve um crescimento exponencial, chegando a 26 serrarias, superando a capital que possuía 21. A partir de 1898 instalou-se a primeira serraria de compensados e laminados em Boa Vista, ampliando a produção inclusive com boa aceitação no mercado externo.

Em relação à produção, Roraima produziu $23.140,83 \mathrm{~m}^{3}$ de madeira em tora em 1984, sendo que $12.551,89 \mathrm{~m}^{3}$ eram madeira serrada. $\mathrm{O}$ índice de aproveitamento da madeira no estado era em média 54,2\%, devido a precariedade dos equipamentos, matéria-prima de qualidade baixa e mão de obra não qualificada; 
os resíduos tinham como destino o fogo, dado o desconhecimento do uso tecnológico, de acordo com Barbosa (1990). Em 1988 a produção somou $40.979 \mathrm{~m}^{3}$ de madeira, sendo 22.227,8 $\mathrm{m}^{3}$ madeira serrada. As fontes para essa produção eram oriundas de frentes de colonização (98\%) e de terras devolutas (2\%).

De acordo com os dados da extração vegetal e silvicultura do IBGE, em 2018 o estado produziu $418.756 \mathrm{~m}^{3}$ de madeira em tora e $89.540 \mathrm{~m}^{3}$ de madeira em lenha. Contou com a participação de todos os municípios do estado, principalmente Rorainópolis, Caracaraí e Caroebe na produção de madeira em tora com $155.942 \mathrm{~m}^{3}, 132.428 \mathrm{~m}^{3}$ e $66.673 \mathrm{~m}^{3}$, respondendo por $84,67 \%$ do total. Em relação a produção em lenha, esta se encontra relativamente distribuída, com participação maior do Cantá (28,47\%), seguido de Rorainópolis (12,28\%), Mucajaí (11,5\%), e Alto Alegre (10,05\%), com participação menor de outros municípios. Com esses dados é possível observar uma inversão ao acorrido na década de 80 , quando a produção se concentrava em Boa Vista.

Em 2018, de acordo com Azevedo (2018) a madeira foi o segundo principal item da pauta exportadora, tendo como principais destinos a Holanda e França. O setor madeireiro contribui de forma relevante com a indústria de transformação de Roraima, em especial na geração de empregos. No primeiro semestre de 2018 ocorreu um saldo negativo de empregos formais, tendo como principal condutor a indústria da madeira e do imobiliário, que apresentou queda no semestre.

\section{RESULTADOS E DISCUSSÃO}

\section{Considerações Sobre o Produto Interno Bruto de Roraima}

Na análise do PIB do Estado de Roraima entre 2002 e 2016, é possível verificar a evolução progressiva do PIB, sendo o de 2010, o maior do período. O Estado ocupa a 27ạ posição no PIB do Brasil no mesmo ano, representando aproximadamente a $0,17 \%$ do PIB nacional, conforme quadro.

Quadro 1: Produto Interno Bruto de Roraima (1 $000000 \mathrm{R} \$$ ).

\begin{tabular}{|c|c|c|c|c|c|c|c|c|c|c|c|c|c|c|c|}
\hline Detalhamento & 2002 & 2003 & 2004 & 2005 & 2006 & 2007 & 2008 & 2009 & 2010 & 2011 & 2012 & 2013 & 2014 & 2015 & 2016 \\
\hline $\begin{array}{l}\text { PIB a preços } \\
\text { correntes (R\$ } \\
\text { milhões) }\end{array}$ & 2.392 & 2.594 & 2.823 & 3.193 & 3.802 & 4.203 & 4.842 & 5.672 & 6.639 & 7.304 & 7.711 & 9.011 & 9.744 & 10.243 & 11.011 \\
\hline $\begin{array}{l}\text { PIB per capita } \\
\text { (R\$ } 1,00)\end{array}$ & 6.737 & 7.066 & 7.391 & 8.161 & 9.427 & 10.622 & 11.730 & 13.457 & 14.714 & 15.872 & 16.424 & 18.462 & 19.608 & 20.256 & 21.414 \\
\hline $\begin{array}{l}\text { Crescimento } \\
\text { real do PIB (\%) }\end{array}$ & - & $1,9 \%$ & $6,7 \%$ & $7,3 \%$ & $9,3 \%$ & $-1,9 \%$ & $6,6 \%$ & $5,7 \%$ & $8,9 \%$ & $3,2 \%$ & $4,8 \%$ & $5,5 \%$ & $2,5 \%$ & $-0,3 \%$ & $0,2 \%$ \\
\hline
\end{tabular}

Fonte: Dados do IBGE (2010).

Ao considerar a participação dos setores na composição do PIB, de 2002 a 2016 observa-se um destaque para o de serviços, seguido da indústria e agropecuária, em média de $85 \%, 11,22 \%$ e 3,6\%. 0 peso da participação no setor de serviços é o setor público (Administração, Saúde, Educação e seguridade social) que participou do PIB em média 49,2\% no período, caracterizando a economia de contracheque.

Quanto à indústria extrativa e de transformação, das quais fazem parte o setor madeireiro, a participação no valor adicionado nas duas indústrias é inferior a 3,5\%, mas não se pode ignorar sua contribuição, tendo em vista seu efeito multiplicador no produto e que quase $50 \%$ é composto pelo setor público. Após este, os destaques são o comércio, atividades imobiliárias e construção.

Percebe-se com o Gráfico abaixo que a indústria de transformação possui maior participação no PIB 
de Roraima em comparação com a indústria extrativa. Enquanto a primeira apresenta um aumento a partir de 2007 a outra decresce em participação no valor adicionado. Não obstante, percebe-se uma elevação progressiva no valor adicionado total da indústria de transformação.

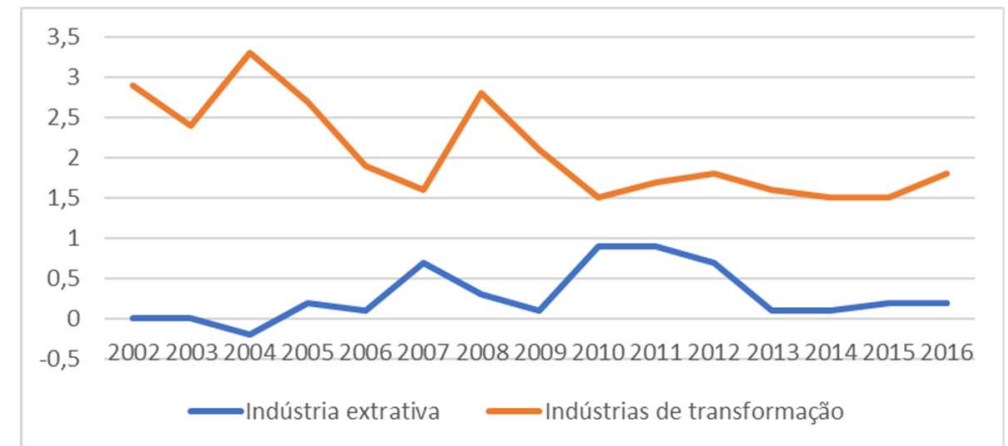

Gráfico 1: Participação no valor adicionado total (PIB). Fonte: IBGE (2016).

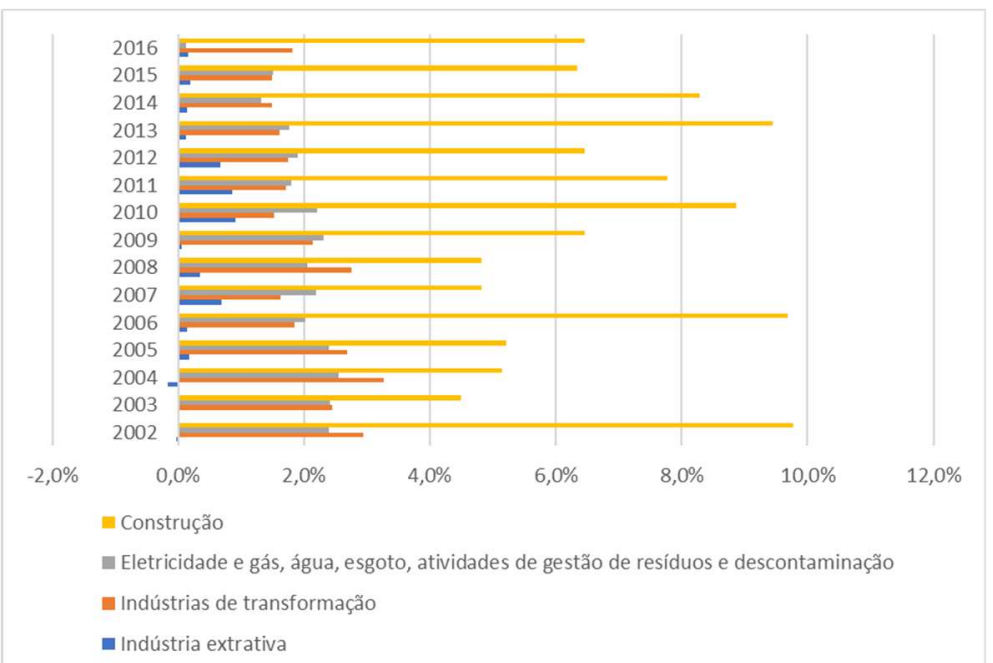

Gráfico 2: Participação da Indústria No Valor Adicionado A Preços Básicos (2002-2016). Fonte: IBGE (2016).

Quanto ao setor industrial, este compõe valores referente à produção e distribuição de energia elétrica, gás, água, esgoto e limpeza urbana; construção civil; indústria de transformação e indústria extrativa. No gráfico 2, é possível perceber que o valor adicionado da construção civil é mais significativo, seguido da indústria de transformação, produção e distribuição de serviços urbanos e indústria extrativa. Quanto à participação do setor madeireiro, este contribui principalmente com a indústria de transformação, apesar de participar do produto na indústria extrativa.

\section{O Setor Madeireiro e sua Contribuição na Geração de Emprego e Renda}

Em janeiro de 2019, o saldo de geração de empregos formais foi maior na indústria de transformação, com saldo de 320, 4 na indústria extrativa e queda em todos os demais setores da indústria, com destaque para o saldo negativo de 253 da construção civil. Em fevereiro do corrente ano a indústria de transformação gerou um saldo positivo de 50 postos de trabalho. A administração pública, a agropecuária e os serviços, também registraram saldo positivo, com menos da metade da indústria de transformação (SEPLAN, 2019).

Apesar da menor participação do setor industrial e agropecuário no PIB, percebe-se que, em 2010, o número de ocupações destes setores supera o do setor público, demonstrando a capacidade desses setores 
de absorver mão-de-obra e gerar renda. Na análise do gráfico 3, é possível verificar a importância da agricultura, pecuária, produção florestal, pesca e aquicultura, em termos do número de pessoas ocupadas com essa atividade. Cabe acrescentar que, além da produção florestal, o setor madeireiro também contribui com a indústria de transformação, na produção de bens móveis de madeira, que são computados na balança comercial, bem como na indústria extrativista, o que demonstra a capacidade do setor de gerar empregos no Estado. Superar o em volume o número de ocupações do setor público é um dado relevante para entender sua importância no contexto da economia de Roraima.

Apesar do pouco dinamismo do setor privado, Bedin (2011) destaca que não se pode negligenciar a sua participação, pois “apesar de se ter setores produtivos com baixo dinamismo, há uma geração secundária de efeitos multiplicadores". Essa geração de efeitos multiplicadores se faz presente pela troca de insumos e produtos entre os setores. Na visão do autor, o multiplicador de produção "indica em quantas vezes a produção cresceu em Roraima nos setores observados e qual foi o setor que gerou os efeitos mais 'fortes' na produção, sendo um bom setor para investimento".

Nesse sentido, percebe-se que apesar do pouco dinamismo do setor privado em Roraima, sua participação no produto tem se ampliado, apresentando o maior crescimento em termos relativos. Sua importância é verificada principalmente na geração de emprego e renda na economia, visto que o número de ocupações no setor supera o do setor público, apesar de este contribuir com uma parcela significativa no PIB.

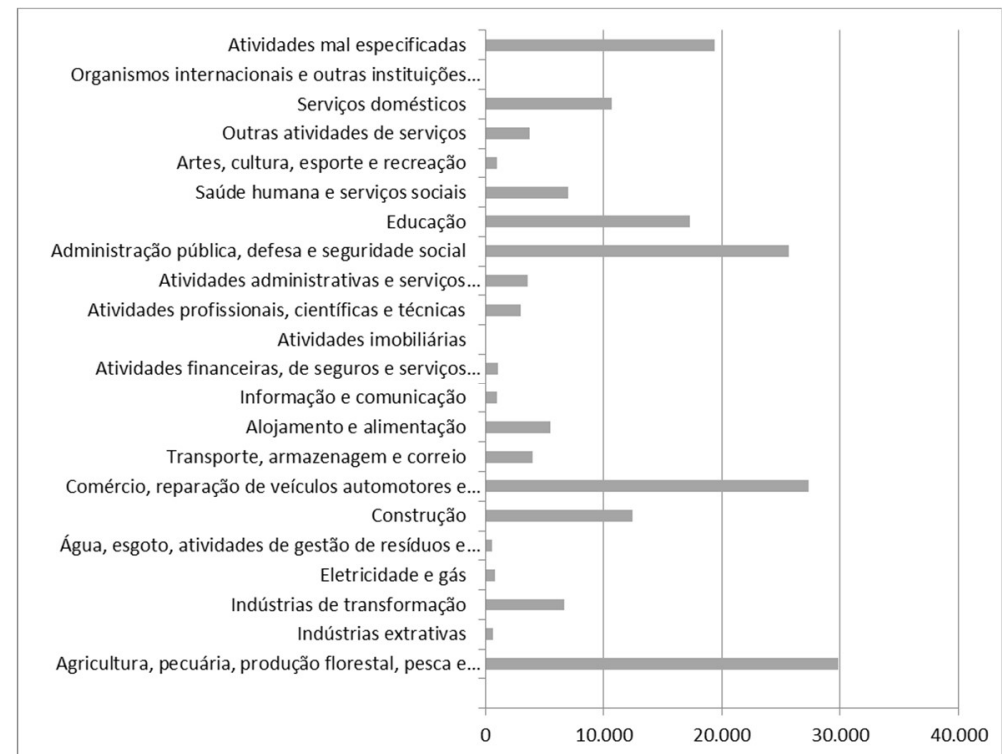

Gráfico 3: Número de pessoas ocupadas por atividade (2010). Fonte: IBGE (2010).

\section{Importância do Setor Madeireiro na Balança Comercial}

Localizado no extremo norte amazônico, Roraima possui uma posição geográfica e estratégica favorável para as relações comerciais. O setor madeireiro tem uma participação significativa nas exportações do estado, levando o setor se adequar às melhores condições de exploração, a fim de que possa garantir mercado e preços para esses produtos (SILVA et al., 2008).

Bendin (2011) afirma o Estado de Roraima passou por fases econômicas distintas que permitiram a delimitação do território e delineou sua estrutura econômica, apresentando o primeiro delineamento com a 
produção pecuária; seguido das atividades de mineração e garimpo e; a consolidação do setor público e a passagem de território federal para ente da federação em 1988, com a Constituição Federal; fase do agronegócio do arroz e soja; elevação da participação do setor de serviços e importações, e por fim, estreitamento das relações com a Zona Franca de Manaus e países vizinhos.

De acordo com Benchimol (1997) "exportar sempre foi a solução para o escoamento da produção da Amazônia desde os tempos coloniais" tendo em vista a variedade de riquezas naturais. A região "somente conseguiu tornar-se viável quando foi possível colocar nos mercados internacionais as matérias-primas e os produtos para os quais não havia suficiente demanda interna ou nacional". Analisando a importância dos recursos naturais o autor complementa:

O melhor aproveitamento e uso dos recursos da biota florestal e animal, da geota mineral e do agropastoreio resultaram num considerável aumento de participação desses setores na exportação regional dos nove estados que compõe a Amazônia legal. Assim é que o total exportado (...) aumentou de US\$ 456,00 milhões em 1983 para US\$3,74 bilhões em $1996 \mathrm{e}$ US\$ 4,24 bilhões em 1997, com incremento de 777,0\% em quinze anos. (BENCHIMOL, 1997)

Em comparação com a evolução das exportações de madeira no mesmo período, é possível observar que esta segue a tendência das exportações totais, apresentando uma inclinação para baixo por conta participação de outros produtos na balança comercial. Em geral, o crescimento das exportações totais entre 1989 e 2012 apresenta-se mais instável que a evolução das exportações de madeira no período.

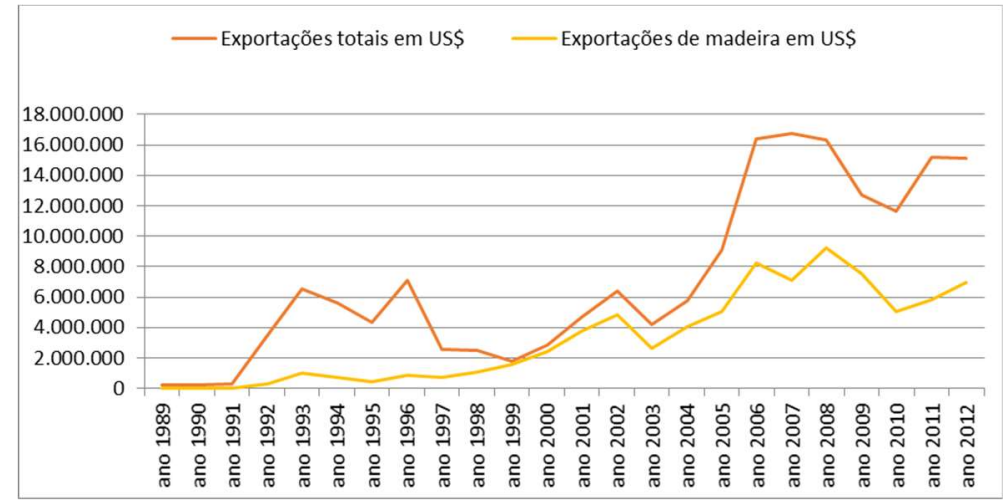

Gráfico 4: Comparação das exportações de Roraima em US\$ com a participação da madeira nas exportações de 1999 a de 2012. Fonte: MDIC (2012).

De acordo com Maia (2010) a queda nas exportações em 2009 acompanha a queda verificada nas exportações brasileiras, e está associada à crise econômica internacional, iniciada nos Estados Unidos, com o pico em 2009. Entre outros resultados, a crise causou retração da demanda por produtos das principais economias mundiais. Em 2011, as exportações se recuperam, porém não alcançam o melhor patamar verificado entre 2006 e 2008.

Analisando os dados da exportação de madeira ${ }^{3}$, no período de 1989 a 2012, é possível verificar a composição da pauta exportadora e a participação da madeira nas exportações totais. Entre 1989 e 1990 a madeira não teve participação, apenas o couro fazia parte da pauta exportadora de Roraima. Em 1991, a madeira já contribui com 7\% das exportações tendo como único destino a Venezuela, enquanto os 93\% eram

\footnotetext{
${ }^{3}$ Nas exportações totais o consumo de bordo no Aeroporto Internacional de Boa Vista (combustíveis e lubrificantes) estão computados como exportação de Roraima, de acordo com o MDIC. No valor das exportações de madeira estão incluídos os produtos fabricados com madeira, tais como portas, janelas, móveis, etc.
} 
diamante destinado à Bélgica. Em 1992, Roraima continua exportando principalmente madeira (8\%) para a Venezuela e diamante (91\%) para Bélgica, Suíça e Estados Unidos, com uma pequena participação produto de limpeza (1\%) para o Paraguai. Em 1993, a madeira já contribuía com 14,6\% destinados à Venezuela e o diamante com 83,6\% para Bélgica, Reino Unido e Suíça, sendo 1,8\% demais produtos (MDIC, 2012).

De 1994 a 1998 o diamante e a madeira continuaram sendo os principais produtos exportados. Em 1999, a madeira respondia por $88,49 \%$ do valor total de produtos exportados, tendo como único destino a Venezuela, com participação menor do diamante $(6,7 \%)$, consumo de bordo (combustíveis e lubrificantes) (2,81\%), e cimento (2\%). Em 2000, a participação da madeira foi de $84,66 \%$, o cimento contribuiu com $8,7 \%$ e o consumo de bordo com 3\%. Em 2001, a madeira contribuiu com 80,22\%, o diamante com 10,29\%, o consumo de bordo com $2,09 \%$, o cimento com $0,26 \%$ e o restante $7,14 \%$, indicando uma maior participação dos demais produtos nos anos seguintes. Em 2002, por exemplo, 75,09\% do valor exportado foi madeira. 0 percentual de participação de 1989 a 2012 pode ser visualizado abaixo.

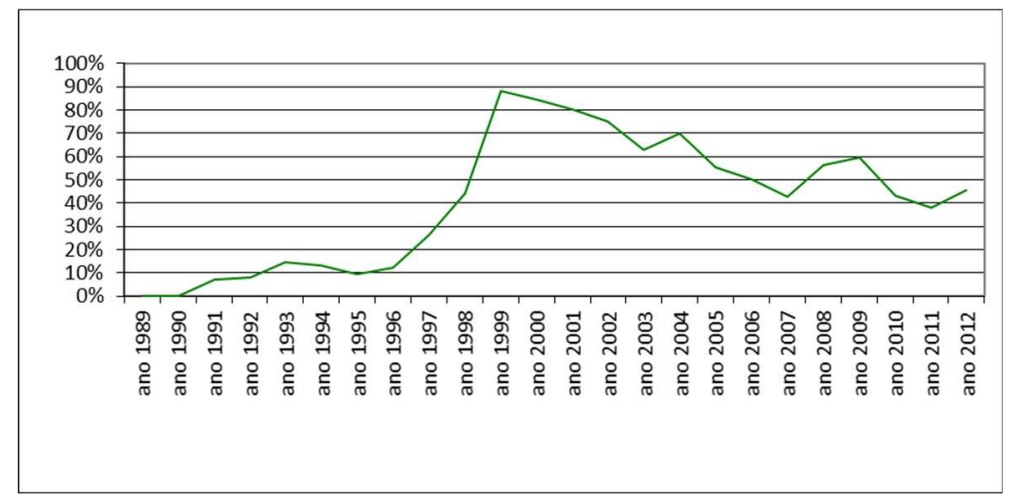

Gráfico 5: Contribuição das exportações de madeira às exportações do Roraima de 1989 a 2012. Fonte: MDIC (2012).

De forma geral, de 1991 a 1999, a madeira contribuiu de forma crescente com as exportações totais. Desde 1999 até 2011 a participação da madeira apresenta uma tendência decrescente, chegando a 63\% do valor exportado em 2003. Em 2004, observou-se um acréscimo, dado que os principais componentes das exportações foi a madeira $(70,10 \%$, ) seguido do couro $(24,80 \%)$, ambos respondendo por quase $100 \%$ dos produtos. A partir de 2004 até 2007 observa-se uma contínua redução do percentual de participação da madeira nas exportações, tendo em vista a participação crescente de outros produtos tais como o couro, consumo de bordo e a soja, que superou a madeira em 2007 com 56,43\% do valor total exportado.

Em 2008 e 2009 a madeira apresenta sinais de recuperação com 56,38\% e 59,51\% do valor total exportado respectivamente, decrescendo em 2010 e 2011. Apesar da redução dessa participação em termos percentuais, os valores das exportações de madeira ainda possuem peso significativo na pauta exportadora, contribuindo, por exemplo, com $45,73 \%$ do valor total de produtos exportados em 2012. Em relação aos demais produtos a relação foi inversa, conforme gráfico 6 .

Como se pode observar, até 1999, a participação de outros produtos na pauta exportadora é mínima. De 2002 a 2011, a participação de outros produtos amplia-se, indicando maior diversificação da pauta exportadora. Entre 2011 e 2012, a participação dos demais produtos na balança comercial cai, tendo em vista o aumento de participação da madeira. A tendência atual, como pode ser observado abaixo, é de aumento 
da participação da madeira nas exportações totais a partir de 2017, após um pico de 40\% em 2015 e queda acentuada em 2016.

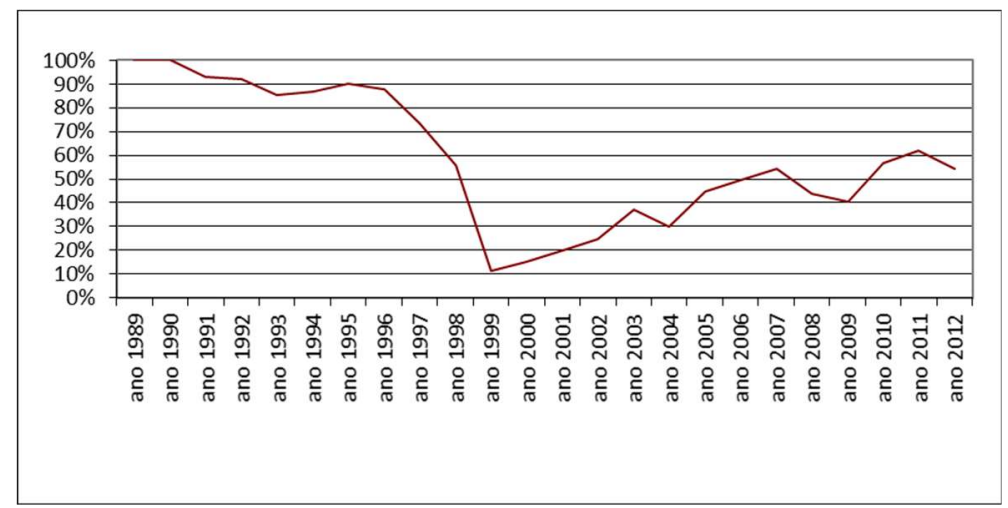

Gráfico 6: Percentual de participação dos demais produtos na pauta exportadora no período de 1999 a 2012.

Fonte: MDIC (2012).

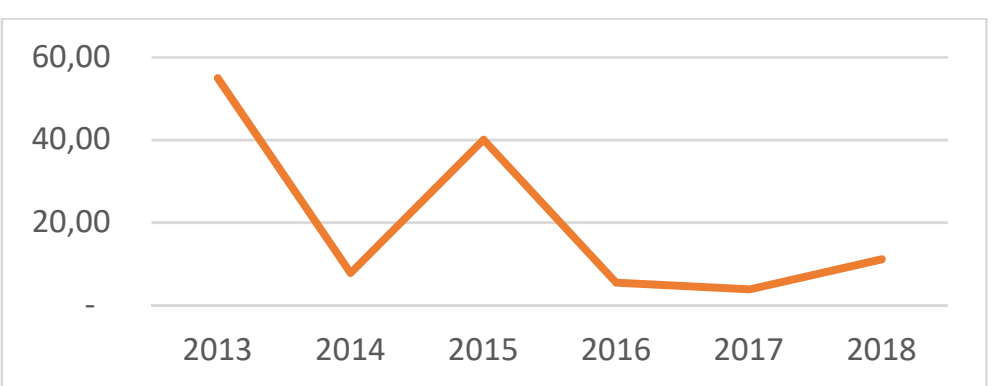

Gráfico 7: Percentual de participação da madeira nas exportações de Roraima (2013 - 2018).

Em relação ao saldo da balança comercial, este se apresenta positivo no período analisado, de 1999 a 2012, com exceção do ano de 2000, que apresentou um saldo negativo de US\$1.995.160. Até 2002 o saldo positivo foi crescente e contínuo, acompanhando a tendência das exportações totais e do incremento do setor madeireiro. Em 2003, o saldo apresenta uma queda, constatada também nas análises anteriores, com progressivo aumento até 2006. Entre 2006 e 2008, o saldo da balança se apresenta instável, da mesma forma que as exportações de madeira, com uma queda brusca em 2009, seguindo a tendência dos gráficos anteriores. A partir de 2011, o saldo da balança comercial apresenta um saldo crescente, trazendo divisas para o Estado de Roraima, ampliando a importância do comércio exterior. De 2013 a 2018, o saldo segue a tendência positiva, acima do verificado em 2012.

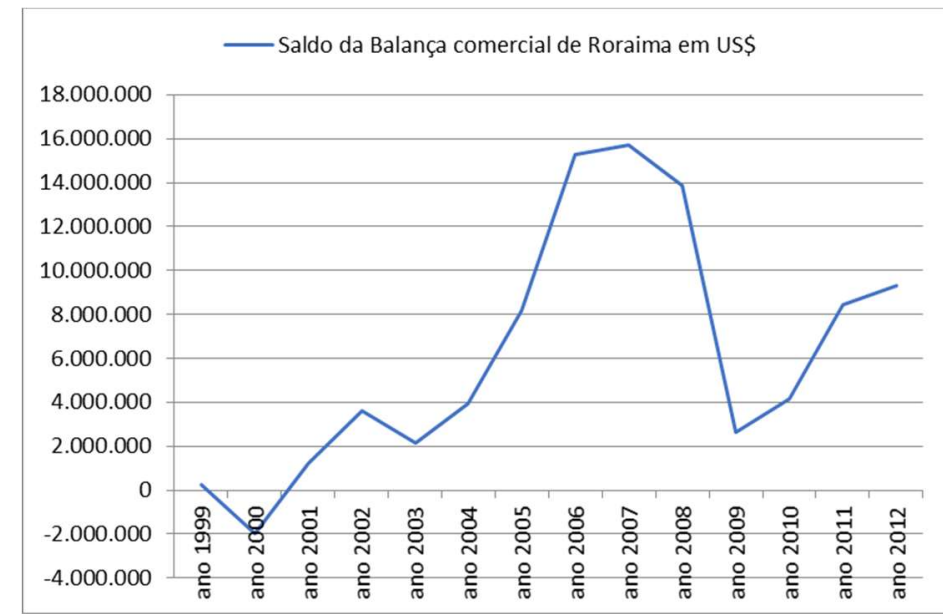

Gráfico 8: Saldo da Balança comercial de Roraima de 1999 a 2012. 
Esses resultados corroboram com a perspectiva de participação dos demais produtos nas exportações, indicando uma diversificação e uma participação mais distribuída entre os itens da pauta exportadora. A participação da madeira tem importância significativa para a formação de divisas para o estado, sendo ainda o principal produto exportado, apesar da participação de outros componentes tais como consumo de bordo, soja, couro e água mineral. Há outros itens com participação pequena, mas a distribuição indica boas perspectivas para o desenvolvimento de outros setores.

\section{CONCLUSÕES}

A importância do setor madeireiro na economia de Roraima verifica-se na geração de efeitos multiplicadores no produto, no emprego e na renda, demonstrando a capacidade do setor em gerar renda e absorver mão-de-obra. Apesar do pouco dinamismo do setor privado, este vem ampliando sua participação no PIB e apresentando o maior crescimento em termos relativos. A análise dos efeitos multiplicadores é relevante na medida em que se estuda setores que podem contribuir com a economia local e gerar um dinamismo na região, atraindo outros setores e atividades em torno. North (1955) explica que o sucesso da base da exportação foi o fator determinante da taxa de crescimento das regiões, e é resultado do papel básico na determinação do nível de renda, na quantidade de atividades locais influenciando ainda em outras indústrias e flutuações na renda e emprego, o que explica a influência seja positiva no emprego em 2018.

Em relação ao comércio exterior, as bases teóricas mais atuais da economia internacional, que leva em conta os benefícios da economia de escala, contribuem para análise do crescimento endógeno e sustentável das economias, gerando inúmeros efeitos e encadeamentos com outros setores. Os dados analisados referente ao comércio exterior madeireiro permitem concluir que este setor contribuiu e continua fornecendo significativas contribuições à balança comercial do Estado de Roraima, contribuindo desde 1991, com apenas 7\% chegando a mais de $80 \%$ em 1999, 45,73\% em 2012, 40\% em 2015 e um pouco mais de 10\% do que foi exportado pelo Estado em 2018. A queda relativa da participação do setor madeireiro na pauta exportadora pode estar associada à efetividade da fiscalização, bem como ser uma resposta à atenção voltada para a preservação do meio ambiente, preocupação que se tornou mais latente após a década de 1980.

Considerando que a cobertura vegetal de Roraima é composta principalmente por florestas, um fator que explica o grande percentual de participação da madeira no comércio exterior é a teoria das vantagens comparativas e modelo Hecsher-ohlin. O primeiro considera a vantagem comparativa na produção de um bem se o custo de oportunidade da produção for menor que em outro país. Por sua vez, o modelo informa que os países se especializam na produção de bens que utilizam fatores de produção abundantes, em troca de bens cujos fatores são escassos.

Dessa forma, isso levaria a uma equalização relativa dos fatos e preços relativos, porém com uma distribuição de renda desigual. A nova teoria do comércio internacional leva em consideração a presença de rendimentos crescentes a escala e de economias externas como forma de aproveitar melhor os benefícios do comércio. Ao considerar-se o perfil do estado e de sua pauta exportadora no período analisado, é possível 
compreender a importância do setor madeireiro para a geração de divisas para o estado, bem como se sua relevância na geração de efeitos multiplicadores no produto, emprego e renda na economia local.

\section{REFERÊNCIAS}

AGNELO, H.. As exportações brasileiras de madeiras tropicais. Tese (Doutorado em Engenharia Florestal) Universidade Federal do Paraná, Curitiba, 1998.

BARBOSA, R. I.. Análise do setor madeireiro do Estado de Roraima. Acta Amazônia, Roraima, v.20, p.193-209, 1990. DOI: http://dx.doi.org/10.1590/1809-43921990201209

BENCHIMOL, S.. Exportação da Amazônia Brasileira. Manaus: Valer, 1997.

BENDIN, S. L.. Correlação entre os setores-chave do desenvolvimento do Estado de Roraima: uma análise tipo insumo-produto. T\&C Amazônia, v.9, n.20, 2011.

CARBAUG, Robert Júnior. Economia Internacional. São Paulo: Pioneira Thomson Learning, 2004. 104p.

IBGE. Instituto Brasileiro de Geografia e Estatística. Extração vegetal e silvicultura 2018. In: Informações dos municípios: Cidades. Brasília: IBGE, 2018.

IBGE. Instituto Brasileiro de Geografia e Estatística. Dados do Estado de Roraima, censo 2010. Brasília: IBGE, 2010.

IBGE. Instituto Brasileiro de Geografia e Estatística. Participação das Grandes Regiões e Unidades da Federação no Produto Interno Bruto 2002-2010. Brasília: IBGE, 2010.

IBGE. Instituto Brasileiro de Geografia e Estatística. Valor adicionado bruto a preços básicos por atividade econômica das Grandes Regiões e Unidades da Federação 2002-2010. Brasília: IBGE, 2010.

INPE. Instituto Nacional de Pesquisas Espaciais. Mapeamento do desmatamento da Amazônia: Projeto Prodes digital. Brasília: INPE, 2018.

MDIC. Ministério da Indústria, Comércio Exterior e Serviços. Exportações de Roraima de 1989 a 2012. Brasília: MDIC, 2012.

MDIC. Ministério da Indústria, Comércio Exterior e Serviços. Balança comercial de Roraima de 1999 a 2012: Sistema Aliceweb. Brasília: MDIC, 2012.
HUMMEL, A. C.; ALVES, M. V. S; PEREIRA, D. VERÍSSIMO, A.; SANTOS, D.. Atividade madeireira na Amazônia brasileira: produção, receita e mercados. Belém: Serviço Florestal Brasileiro, 2010.

KRUGMAN, P.; HELPMAN, E.. Market Structure and Foreign Trade: Increasing Returns, Imperfect Competition and Goreign Trade. Boston: MIT Press, 1985.

KRUGMAN, P. R.; OBSTFELD, M.. Economia Internacional: teoria e política. 6 ed. São Paulo: Pearson Wesley, 2005.

KRUGMAN, P.; VENABLES, A. J.. Integration and the competitiveness of peripheral industry. Cambridge: University Press, 1990.

MAIA, J. M.. Economia Internacional e Comércio exterior. 14 ed. São Paulo: Atlas, 2010.

MAGALHÃES, M. G. S. D.. Amazônia: extrativismo vegetal no sul de Roraima: 1943-1988. Boa Vista: UFRR, 2008.

NORTH, D. C.. Location Theory na regional economic growth. Jornal of Political Economy, v.63, n3, p.243-58, 1955.

PARENTE, V. M.; JÚNIOR, A. R. O.. Potencialidades regionais: estudo de viabilidade econômica de produtos madeireiros. Londrina: ISAE, 2003.

PEREIRA, D.; SANTOS, D.; VEDOVETO, M.; GUIMARÃES, J.; VERÍSSIMO, A.. Fatos florestais da Amazônia 2010. Belém: Imazon, 2010.

SEPLAN. Secretaria de Estado do Planejamento. Artigo técnico no 001/2019: Emprego formal. Boa Vista: SEPLAN, 2019.

SILVA, A.. Economia Internacional: uma introdução. São Paulo: Atlas, 1987.

SILVA, N. C.; SILVA, G. F. N.. Contribuição do setor madeireiro à balança comercial do estado de Roraima: contexto econômico e ambiental. Revista Acta Geográfica, v.2, n.3, p.85-91, 2008.

A CBPC - Companhia Brasileira de Produção Científica (CNPJ: 11.221.422/0001-03) detém os direitos materiais desta publicação. Os direitos referem-se à publicação do trabalho em qualquer parte do mundo, incluindo os direitos às renovações, expansões e disseminações da contribuição, bem como outros direitos subsidiários. Todos os trabalhos publicados eletronicamente poderão posteriormente ser publicados em coletâneas impressas sob coordenação da Sustenere Publishing, da Companhia Brasileira de Produção Científica e seus parceiros autorizados. Os (as) autores (as) preservam os direitos autorais, mas não têm permissão para a publicação da contribuição em outro meio, impresso ou digital, em português ou em tradução. 